\title{
Shape Grammar and Social Housing: recognizing patterns in favelas' buildings
}

\section{SIGRADI2018 TECHNOPOLITICAS \\ xxii congresso da sociedade iberoamericana de gráfica digital 22th conference of the iberoamerican society of digital graphics 07|08|09|novembro|2018 iau usp | são carlos | sp br}

\author{
Margaret Lica Chokyu \\ Faculdade de Arquitetura e Urbanismo - UFRJ | Brazil | margaret.lica@fau.ufrj.br
}

\begin{abstract}
Social Housing is worldwide problem, especially in underdeveloped countries. In Brazil, people do solve this issue with self-made houses, in irregular land occupations. As a result, those informal settlements, also known as favelas, proliferate in medium and big cities all over the country, in very poor infrastructure. On the other hand, governmental policies for social housing development are often criticized, because of several reasons, including architectural design, frequently unfit for the families assisted. The present work observes the architecture developed in self-made houses at Favela da Rocinha and presents Shape Grammar as an instrument for analysis of frequent solutions, in order to provide data for adequate architectural design.
\end{abstract}

Keywords: Shape grammar; Favelas; Informal architecture, Teaching observation.

\section{INTRODUÇÃO}

Favelas são frequentemente vistas como problemas dentro das cidades brasileiras, seja pela carência das condições de vida da população, seja pelo estigma da violência urbana. Entretanto, esses agrupamentos surgem como resposta ao déficit de ações governamentais no setor habitacional e acabam por solucionar uma necessidade básica destas populações: a necessidade de moradia. Os programas governamentais, além de insuficientes em termos quantitativos, sofrem muitas críticas do ponto de vista qualitativo: málocalização com relação à malha urbana existente, baixa qualidade construtiva e projetos de arquitetura equivocados. O propósito deste artigo é explorar a arquitetura das casas autoconstruídas em favelas como referência para projetos de Habitação de Interesse Social (HIS), através do desenvolvimento de metodologia de análise e síntese baseada na Gramática da Forma. O corpus de análise é formado por casas na Favela da Rocinha, na Cidade do Rio de Janeiro. A partir dos exemplares estudados percebeu-se que dentro de um aparente caos há padrões de composições de layouts e de volumetria, que mostram as soluções construtivas adotadas e refletem um modo de viver típico dos habitantes desta área.

A Gramática da Forma tem sido empregada para análise de arquitetura residencial desde a década de 1970, com o trabalho de Stiny e Mitchell para as vilas de Palladio (1978). Depois, Koning e Eizenberg (1981) analisaram as casas de Pradaria de Frank Lloyd Wright, numa primeira análise tridimensional de um conjunto arquitetônico. Além disso, esta Gramática categoriza os espaços funcionais das casas, demonstrando como as diferentes zonas se articulam. Nos primeiros anos dos anos 2000, Duarte estuda o conjunto da Quinta da Malagueira, de Siza Vieira, também numa análise tridimensional e funcional das habitações. E leva a discussão mais longe, problematiza a questão do déficit de moradias no mundo e sobre como métodos computacionais, e em particular aqueles que aplicam a Gramática da Forma, podem auxiliar com o barateamento dos custos de projeto com a manutenção da qualidade. Em 2005 avança para o estudo de arquiteturas informais, com o estudo das Medinas de Marrakech, quando produziu duas gramáticas complementares: desenho urbano e arquitetura.

No Brasil, Andrade et all. (2012) analisaram o projeto do arquiteto Demetre Anastassakis para o bairro de Jardim São Francisco, na cidade de São Paulo. Houve o inferimento de regras da Gramática do Conjunto e a comparação com os projetos de Siza para a Malagueira e de Christopher Alexander no México (1976). Há trabalhos também tendo, como corpus de análise, arquitetura informal, tal como a pesquisa de doutorado em andamento de Débora Verniz na Penn State University a respeito da Favela de Santa Marta, também no Rio de Janeiro.

\section{A ROCINHA}

A Favela da Rocinha localiza-se na Zona Sul do Rio de Janeiro, entre os bairros da Gávea e de São Conrado, sobre a montanha que os separa. A ocupação da área remonta às primeiras décadas do século $X X$, a partir de loteamentos habitacionais privados (Toledo, Natividade, \& Vrcibradic, 2014). No entanto, os empreendimentos faliram e iniciaram-se assim as ocupações ilegais, que se intensificaram a partir da década de 1960 com a abertura da autoestrada Lagoa Gávea, via que liga as zonas sul e oeste, dois importantes polos econômicos da cidade. O túnel Dois Irmãos, integrante desta via, tem saída sob uma das vertentes da Rocinha. Atualmente, possui a favela tem cerca de 70 mil habitantes, configurando-se como a mais populosa do Brasil (IBGE, 2011). 


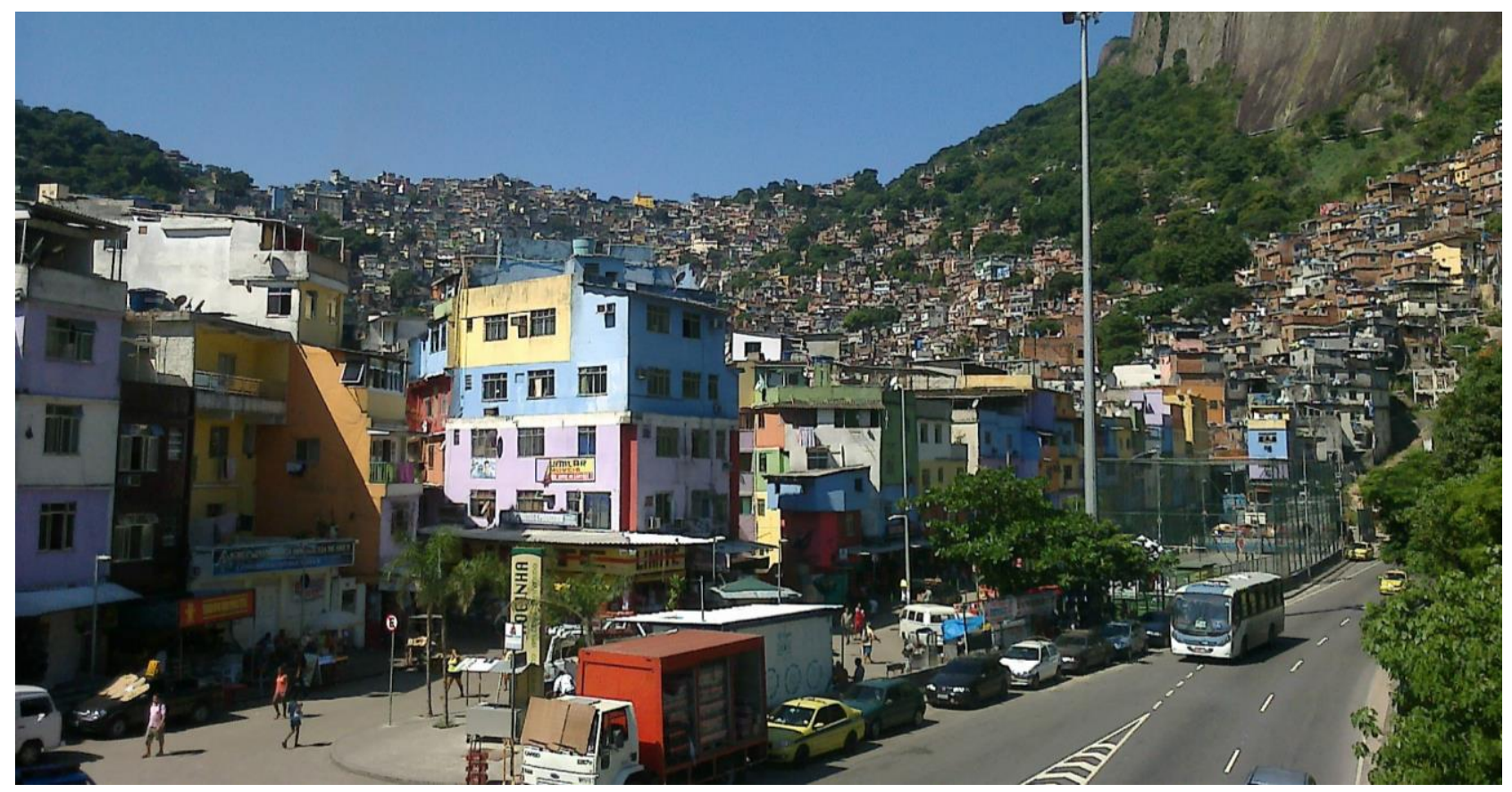

Figura 1: vista da Rocinha, a partir de passarela sobre a Autoestrada Lagoa-Barra. Fonte: Autora.

A Rocinha foi decretada bairro pela prefeitura da Cidade do Rio de Janeiro em 1993, o que permitiria a legalização das construções existentes, além de possibilitar a criação de legislação própria. Diversas ações de melhoramentos já haviam ocorrido desde a década de 1970, sendo que a última foi ocorreu nas primeiras décadas deste século, a partir da elaboração de um Plano Sócio-espacial, que estabelece regras para melhoria da infraestrutura urbana e para reordenação do uso do solo, de maneira a produzir espaços livres. Entre as obras executadas está o alargamento da Rua 4, que era um beco estreito e foi transformado em via carroçável. Foram construídos edifícios novos para abrigar os moradores que tiveram os imóveis desapropriados. Todos os apartamentos dos edifícios construídos possuem 2 quartos, muito embora os imóveis desapropriados tivessem configurações diversas. O projeto reflete a falta de preocupação dos gestores com relação às particularidades de cada família atendida.

\section{GRAMÁTICA DA FORMA E HIS}

A Gramática da Forma (Shape Grammar) foi criada no princípio da década de 1970 por Stiny e Gips, que vislumbravam o desenvolvimento de metodologias computacionais que permitissem a análise e produção de formas. Estas seguiriam nos mesmos princípios descritos por Noam Chomsky, em Syntactic Structures (Chomsky, 1957). Nesta obra, Chomsky analisa as estruturas sintáticas da língua inglesa como operações lógicas de alteração de uma situação inicial de acordo com condicionantes. Estas regras descritas por Chomsky demonstram a forma como por exemplo orações e sentenças são formadas. Na gramática proposta por Stiny e Gips, tais operações envolvem formas em vez de símbolos (letras), alteradas por transformações euclidianas. Uma Gramática da Forma é composta por um conjunto de regras aplicadas algoritmicamente sobre um vocabulário de formas. O algoritmo inicia-se com uma forma inicial. As regras se sucedem até a obtenção de uma forma final.
Assim, foram desenvolvidos trabalhos de análise e síntese em vários campos, inclusive arquitetura, a partir da observação de padrões de composição de elementos da mesma família, de forma a se construir um conjunto de regras que definem uma gramática para esta linguagem. As regras, aplicadas na forma de algoritmo sobre uma forma inicial geram uma nova forma. Assim, um algoritmo pode tanto reproduzir um elemento do conjunto estudado quanto produzir um novo, que pode ser reconhecido como sendo da mesma família.

Duarte (2005), ao analisar o conjunto da Malagueira, do arquiteto português Álvaro Siza Vieira, discute a produção de projetos personalizados em massa, que poderiam ser realizados com ajuda do computador, a partir de um conjunto de regras de composição. Para a elaboração deste, emprega aquelas observadas no referido conjunto, como um referencial projetual. Duarte pondera, ainda, a questão do déficit habitacional em todo o mundo, e na necessidade de ferramentas que ajudem na produção de projetos, com custo mais baixo por unidade, mas ainda com possibilidade de personalização.

No Brasil, os empreendimentos de habitação popular poderiam se beneficiar da possibilidade de personalização de projetos através de métodos computacionais. O mais usual nas obras de HIS é a utilização de um único modelo repetido dentro do conjunto, sem a consideração de diferentes arranjos familiares. E normalmente não são considerados, tampouco, questões sociais e culturais nos projetos. Os projetos de HIS desenvolvidos por Anastassakis e analisados por Andrade et all. (2012) configuram-se como parte das exceções a este padrão. O arquiteto valoriza a diversidade tipológica e tal fato motivou o estudo de uma gramática da forma e a comparação com os trabalhos de Siza e Alexander. Nesse sentido, um conjunto de regras pode facilitar a personalização de projetos de Habitação de Interesse Social. Essas regras, baseadas em padrões existentes nas habitações autoconstruídas, deveriam tornar os projetos também culturalmente mais próximos do público-alvo. Assim, em 
vez de se buscar um projeto de arquiteto na área, fez-se análise das soluções obtidas pelos próprios moradores nas favelas.

\section{GRAMÁTICA DA FORMA NA ROCINHA}

Este trabalho integra uma pesquisa realizada pelo grupo de pesquisas Educação do Olhar, integrante do PROARQ/FAU-UFRJ, que estudou a Rocinha sob a ótica da Gramática da Forma. Foram analisados o traçado urbano e as construções da favela, sendo que esta última é o foco do presente artigo.

O estudo ora apresentado define uma Gramática da Forma das edificações residenciais da Favela da Rocinha. As regras foram inferidas a partir da observação de padrões de composição dos espaços. Esta análise considerou também as funções dos ambientes que compõem as residências, a exemplo de trabalhos como "The language of the Prairie" (Eizenberg \& Koning, 1981) e "Towards the mass customization of housing" (P Duarte, 2005), onde as funções dos espaços desempenham papel importante na definição das regras. No primeiro, as formas acrescidas às existentes também recebem uma indicação de função. No caso das casas da Malagueira, onde ocorrem subdivisões recursivas dos espaços, estas operações ocorrem também com a sinalização de zoneamento, interior e exterior, que vão sendo substituídas por funções mais específicas, à medida em que as operações se sucedem.

Esta abordagem é a mesma empregada no presente trabalho: foi observado como se dá a distribuição das funções na casa, assim como as soluções de construtivas. Entende-se que a maneira como são compostos os espaços funcionais é justamente a tradução do conceito do morar destes habitantes, e esta compreensão pode ser a chave de projetos mais adequados.

\section{CORPUS DE ANÁLISE}

O corpus de análise é constituído de 10 unidades habitacionais, todas situadas dentro do mesmo setor na Rocinha, o Al2, que também foi o foco de estudo da pesquisa de traçado urbano realizado pelo grupo. Estas residências localizam-se em 6 edificações diferentes, a maior parte delas situadas em becos estreitos. As casas são geralmente construídas e ampliadas ao longo dos anos. Os edifícios estudados são diversificados, como se pode observar no quadro abaixo. Alguns são unifamiliares, com uma única unidade para todo o prédio. Outros possuem mais de uma unidade, havendo ainda diferentes relações de propriedade dentro desta mesma tipologia: alguns tem um único proprietário para todas as unidades, que os aluga para os demais habitantes. Em outros, as unidades pertencem a indivíduos distintos. Há uma prática comum chamada de "direito de laje", onde uma pessoa vende o espaço sobre seu próprio imóvel (a laje) a outra, que poderá, portanto, construir sua própria casa, como se tivesse adquirido um lote.
Tabela 1: quadro das edificações estudadas

\begin{tabular}{|c|c|c|c|c|}
\hline Edific. & $\begin{array}{c}\text { № } \\
\text { pavtos. }\end{array}$ & $\begin{array}{c}\mathrm{N}^{\circ} \text { de } \\
\text { unidades }\end{array}$ & $\begin{array}{c}\text { cômodos } \\
\text { longa } \\
\text { permanência } \\
\end{array}$ & Área $\left(\mathrm{m}^{2}\right)$ \\
\hline 1 & 4 & 1 & 5 & 100 \\
\hline 2 & 6 & 4 & $\begin{array}{ll}\text { ap.1: } & 3 \\
\text { ap.2: } & 2 \\
\text { ap.3: } & 2 \\
\text { ap.4: } & 3\end{array}$ & $\begin{array}{l}37,9 \\
27,3 \\
30,6 \\
87,5\end{array}$ \\
\hline 3 & 5 & 1 & 5 & 182,5 \\
\hline $4^{*}$ & ** & ** & 1 & 24,9 \\
\hline $5^{*}$ & $* *$ & ** & 1 & 25,2 \\
\hline 6 * & 5 & 6 & $\begin{array}{ll}\text { ap. } 1: & 4 \\
\text { ap.2: } & 2\end{array}$ & $\begin{array}{l}57,0 \\
32,7\end{array}$ \\
\hline
\end{tabular}

$\left.{ }^{*}\right)$ demais imóveis da edificação não foram acessados.

$\left.{ }^{* *}\right)$ não foi possível determinar.

As casas foram medidas e fotografadas, observando-se também, à medida do possível, a relação dos imóveis a que pertencem com os demais do entorno. Na maior parte dos imóveis, não há relação entre plantas de pavimentos distintos. Cada unidade é construída de maneira independente e as alvenarias erguidas sobre as lajes existentes não guardam, em boa parte das vezes, relação com as localizadas logo abaixo, uma vez que não há, necessariamente, conhecimento do imóvel inferior.

Alguns edifícios na Rocinha, em razão da forma de crescimento destes, sem exato respeito ao que se entenderia como limites do lote, faz com que alguns imóveis fiquem ocultos por trás de outros, impossibilitando a compreensão da volumetria do edifício

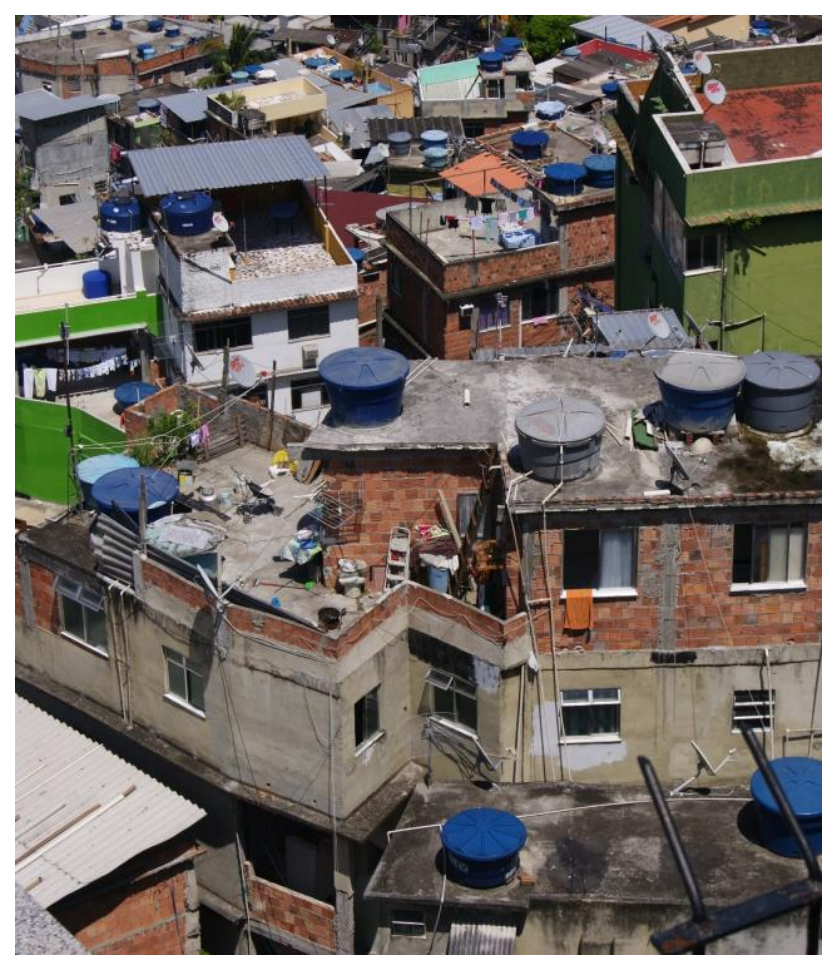

Figura 2: aspecto geral das edificações da Rocinha. Fonte: Autora.

pelo lado de fora. Mas o que se constatou, de uma forma geral, é que alguns elementos de fachadas, afastamentos 
e soluções de instalações se repetem, e por isso foram consideradas na fase de definição de regras.

Alguns elementos puderam também ser constatados numa observação das edificações pelo lado de fora, como o uso do topo das construções como área útil. A chamada "laje" faz as vezes de quintal das habitações e é usada atividades como secagem de roupas ou lazer. As caixas d'água são instaladas sempre nas partes mais altas, e a quantidade existente sobre uma construção costuma ser equivalente ao número de pavimentos. As tubulações que alimentam as unidades não são embutidas na alvenaria, mas comumente pelo lado de fora.

\section{PADRÕES OBSERVADOS E REGRAS INFERIDAS}

Durante a fase de análise, percebeu-se que a cozinha fica, na maior parte das vezes, no fundo do imóvel, com o
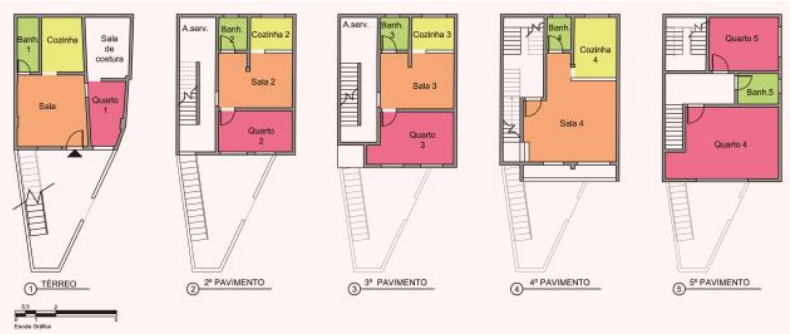

Figura 4: plantas de uma das edificações levantadas. Fonte: Autora.

banheiro contíguo a este. A área de serviço, elemento comum na maior parte das casas da chamada cidade formal, muitas vezes não existe nestes imóveis, e quando há, localiza-se na "laje" ou no quintal. A sala de estar costuma ficar na parte da frente do lote. Não se observaram unidades sem banheiro, mas não é incomum a existência de dois em unidades com 3 ou mais quartos ou naquelas de mais de um pavimento. As escadas são normalmente bastante íngremes, na maior parte com desenho irregular e fora das regras usuais de dimensionamento e não raro o vão na laje para a subida tem dimensões reduzidas, obrigando o usuário a abaixar a cabeça para não se ferir.

Com relação à ocupação do solo, a maior parte dos imóveis ocupa todo o terreno, mas há a ocorrência, ainda que rara, de uma pequena área livre, normalmente murada. Embora, à primeira vista, as edificações pareçam justapostas, normalmente há um pequeno vão entre estas, que varia entre 20 e 30 centímetros de largura. Alguns vãos de ventilação (janelas ou similares) são voltados para estes pequenos espaços, embora não se saiba se estas janelas tenham sido abertas deliberadamente para esses espaços ou se a casa vizinha foi ampliada após. É comum a invasão do espaço acima do nível térreo dos becos. A casa, a partir do segundo pavimento, tem a planta ampliada de maneira a cobrir parcialmente ou totalmente o beco, formando túneis das vias públicas. Estas situações são críticas, a falta de espaço para ventilação e insolação, seja entre as construções, seja nas vias públicas, gera um ambiente altamente insalubre, que se reflete na saúde pública. Um exemplo é o alto número de casos de tuberculose nesta favela (Betim, 2015).
As regras inferidas foram divididas em seis estágios: (1) ocupação do lote, (2) compartimentação dos espaços, (3) realinhamento das alvenarias, (4) abertura de vãos (5) inserção de novos pavimentos e (6) fim. Os estágios tiveram por base, além das Gramáticas da Malagueira ( $P$ Duarte, 2005) e da Pradaria (Eizenberg \& Koning, 1981), a Gramática de Palladio (Stiny \& Mitchell, 1978).

O estágio 1 (Tabela 2) inicia o processo a partir da forma inicial, que é o próprio lote - representado por um retângulo apenas para ilustrar de maneira genérica. A forma específica do lote deverá ser obtida em regras da gramática de traçado urbano, definida em outro momento. As regras deste e do estágio subsequente baseiam-se na subdivisão sucessiva das formas, com troca de cor e/ou inserção de marcador após cada operação. O lote pode ser completamente ocupado (R1), caracterizado pela
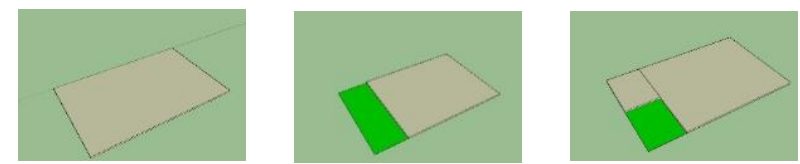

Figura 3: arranjos possíveis após estágio 1. Fonte: Autora.

inserção de uma laje de piso em toda a área do lote, ou pode ter parte deste como área livre (R2). Neste caso, o lote é dividido, parte com a laje, parte com o quintal, que ainda pode ter parte integrado à área construída(R3).

Tabela 2 : forma inicial e regras do Estágio 1

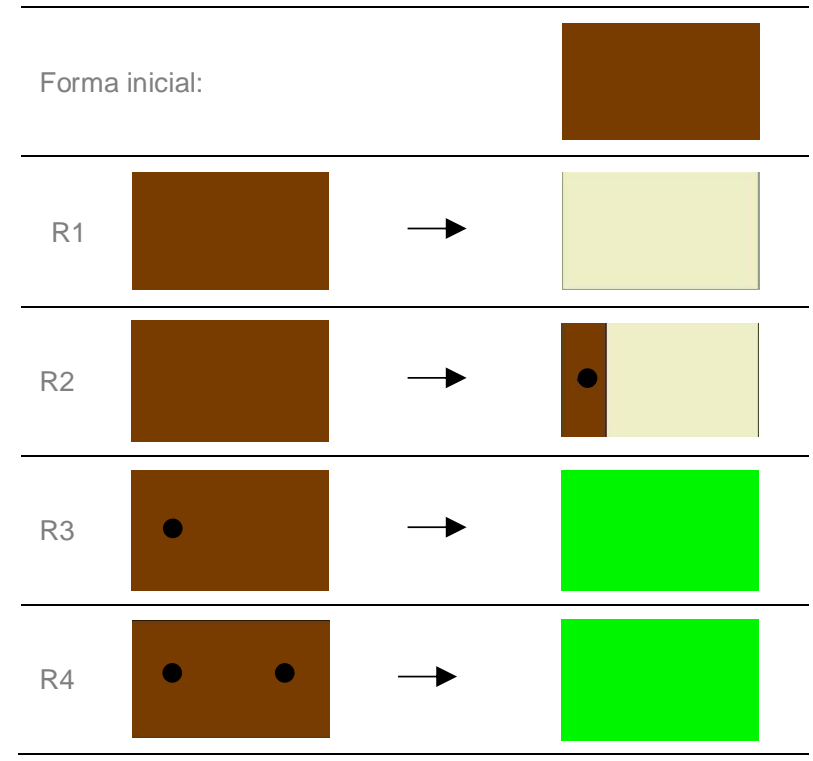

O estágio 2 (Tabela 3 ) cria o layout dos pavimentos, através também de divisões recursivas da forma. As regras iniciais definem as áreas privativas, separando-a da área de circulação coletiva, quando for o caso. A sucessão de divisões permite a geração de diversas unidades residenciais num mesmo pavimento. Depois, ocorre a subdivisão que cria e separa, em cada unidade, as zonas seca (que dará origem aos quartos e sala) da molhada (cozinha e banheiro). A fase de subdivisão se encerra com a especificação final de função de cada espaço (indicada pela cor de preenchimento), quando há também a inserção de uma letra, usada como marcador (label), que indica o início do estágio seguinte. 
Tabela 3: regras do Estágio 2

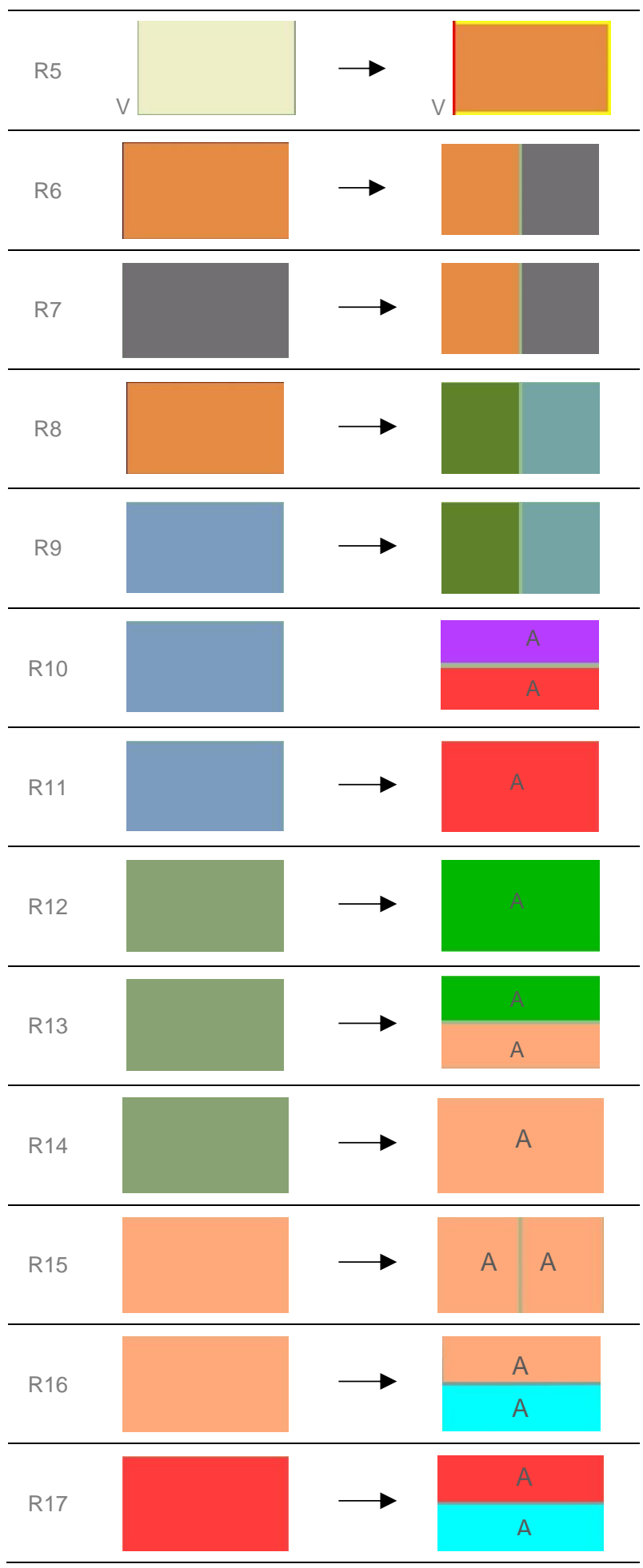

O estágio 4, de realinhamento de alvenarias, possui parâmetros para dimensionamentos mínimos de ambientes como cozinha e banheiro, assim como para os afastamentos para a edificação vizinha. Estes parâmetros foram definidos tendo como base valores obtidos durante o levantamento, sem juízo qualitativo. Os realinhamentos são acompanhados de troca de marcadores, que mais uma vez desempenham o papel de desencadear 0 próximo estágio, o de inserção de vãos de portas e janelas.

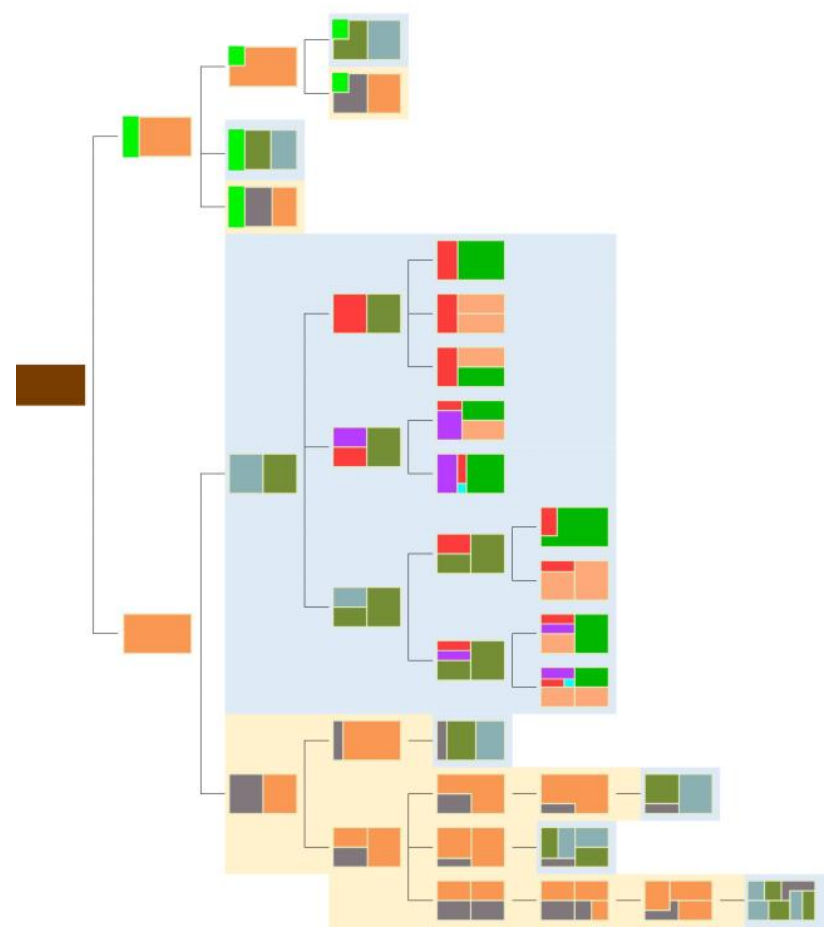

Figura 6: diagrama em árvore - produção de soluções de layout. Fonte: Autora.

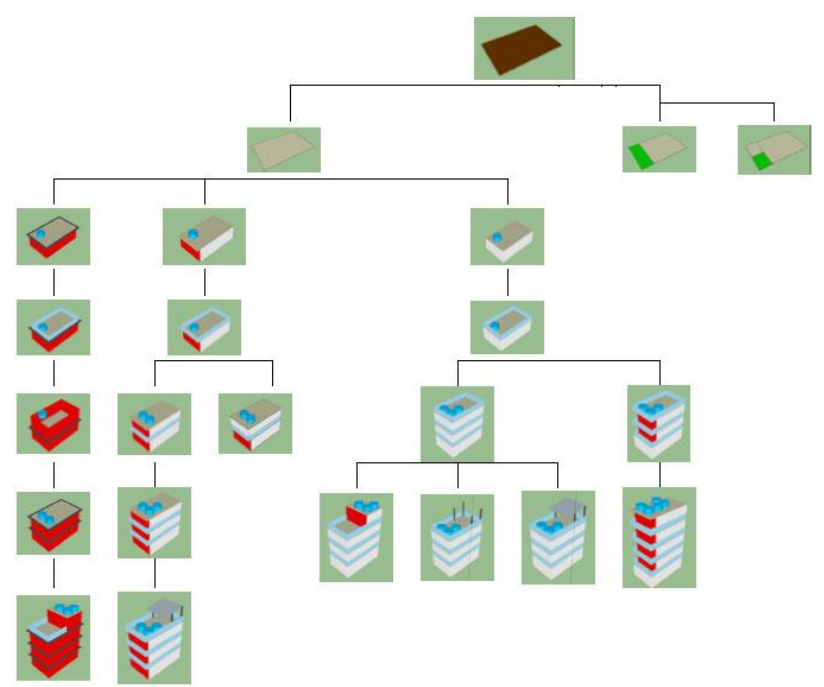

Figura 5: diagrama em árvore - estágio 5, inserção de pavimentos. Fonte: Autora.

Os estágios 2 ao 4 tratam da definição de planta de um pavimento, e acontece de maneira mais ou menos independente do estágio 5 , que produz a volumetria. Embora teoricamente este estágio devesse ocorrer a partir da finalização do estágio 4 , o que se percebe é que nem sempre as alvenarias externas alinham-se entre um piso e outro. Por isso, o estágio 5 pode iniciar-se logo após a aplicação da regra 5. O diagrama em árvore apresentado na Figura 6 ilustra diferentes arranjos volumétricos, que podem ser obtidos independentemente da aplicação das regras dos estágios anteriores. Isso se deve ao fato de os pavimentos não terem as plantas necessariamente relacionadas. As estruturas são normalmente superdimensionadas, incluindo as lajes, que costumam suportar as alvenarias do piso superior sem que as estejam alinhadas. É interessante destacar que a maior parte das pessoas que constroem as casas são 
trabalhadores do setor da construção civil e possuem conhecimento empírico, embora não tenham qualquer educação formal na área.

Foram feitas diversas computações das regras inferidas, que produziram não apenas os exemplares do corpus de análise como também novos. Na Figura 5, o diagrama em árvore demonstra diversas soluções de layout produzidas a partir das regras inferidas. A forma inicial dá origem a duas ocupações de terreno possíveis no primeiro estágio. A primeira destas ainda produz uma outra possibilidade de ocupação do lote. As regras no ramo amarelo mostram soluções para quantidades diferentes de unidades habitacionais dentro de um mesmo pavimento. As computações deste ramo demonstram apenas até a fase de subdivisão das áreas seca e molhada. Para cada uma destas unidades podem ser aplicadas soluções de plantas como as da área azul da árvore, que apresentam soluções de layouts de pavimentos.

A exemplo das Gramáticas usadas como base, a quantidade de soluções possíveis é muito grande, não sendo possível representar todas. Esse fato mostra que a esta Gramática é capaz de produzir um número muito grande de soluções, todas baseadas no corpus analisado, e são, portanto, soluções similares às encontradas pelos próprios moradores da Rocinha.

\section{DISCUSSÃO}

A produção de moradia para a população de baixa renda deve levar em consideração as características desta, sob risco de se fazer projetos inadequados ao público-alvo. No momento atual, face à ineficácia das políticas públicas no setor, muitos têm na autoconstrução a solução para a carência de moradia, e as constroem de acordo com seus conceitos de habitar, embora com inúmeros problemas técnicos. A Gramática da Forma foi aqui proposta para o desenvolvimento de uma metodologia objetiva de análise morfológica que consiga traduzir em regras a maneira de habitar própria dos moradores da Rocinha. Esta metodologia foi inspirada naquela desenvolvida para as residências projetadas por Siza Vieira para a Malagueira (P Duarte, 2005). Entretanto, em vez de estudar um conjunto projetado por um arquiteto consagrado, esta Gramática se debruça sobre uma arquitetura informal, produzida pelos próprios moradores.

Apesar de tal abordagem, reconhecemos que as habitações analisadas estão longe do ideal. A falta de conhecimento técnico na construção gera inúmeros problemas. A Favela da Rocinha, como outras favelas, tem más condições de habitação. Essa situação é devida a fatores como infraestrutura urbana precária ou mesmo inexistente, principalmente fornecimento de água canalizada e saneamento básico. Entretanto, a arquitetura também tem papel importante, a falta de ventilação e de insolação tornam as habitações ainda mais insalubres. Portanto, reproduzir simplesmente as regras extraídas sem qualquer crítica seria no mínimo irresponsável. Os parâmetros para dimensionamentos apresentados, obtidos a partir das medidas aferidas nos levantamentos, não impedem a produção de espaços de má-qualidade, pela não-observância de distâncias mínimas que permitam boa ventilação ou insolação. A Gramática aqui apresentada não está, portanto, pronta para uso. Para que possa produzir bons projetos, são necessárias adequações nos valores dos parâmetros, que deveriam incluir também uma adequação na Gramática do traçado urbano.

Entende-se, também, que a Gramática da Rocinha pode ser não apenas uma ferramenta de auxílio a projetos a serem construídos pelo poder público, mas também para assistência técnica de auxílio a pessoas que vão construir, elas mesmas, as próprias habitações. As regras podem agilizar o processo do projeto e consequentemente baratear os custos, ou ainda ser base para desenvolvimento de ferramentas digitais que possam tornar o processo de projeto ainda mais rápido e eficiente. Interessante também notar que, como as regras baseiam-se no construir e morar próprios da área analisada, é também compatível com o orçamento dos moradores que virão a construir.

O que se espera, finalmente, é que uma ferramenta digital possa efetivamente ser viabilizada a partir destas regras inferidas e que tal fato possa democratizar projetos de arquitetura para a população baixa renda, que poderá a contar com projetos tecnicamente corretos e adequados à sua realidade social e econômica.

\section{AGRADECIMENTOS}

A autora agradece as estudantes Ariane Beltrão e Julia Valente pelo auxílio nos levantamentos das habitações.

\section{REFERÊNCIAS}

Andrade, M., Mendes, L., Godoi, G., \& Celani, G. (2012). Shape Grammars for Analyzing Social Housing - The case of Jardim São Francisco low-income housing development. Em $\mathrm{H}$. Achten, J. Pavlicek, \& D. Matejovska, Digital Physicality Proceedings of the 30th eCAADe Conference - Volume 1 (pp. 451 - 458). Praga: Czech Technical University in Prague, Faculty of Architecture.

Betim, F. (12 de setembro de 2015). El País. Fonte: https://brasil.elpais.com/brasil/2015/09/01/politica/144112019 8_053979.html

Eizenberg, J., \& Koning, H. (1981). The Language of the Prairie: Frank Lloyd Wright's prairie houses. Environment and Planning B, 8, pp. 295-323.

IBGE. (2011). Aglomerados Subnormais: primeiros resultados. Rio de Janeiro: IBGE.

P Duarte, J. (2005). Towards the mass costumization of housing: the grammar of Siza's houses at Malagueira. Environment and Planning B: Planning and Design, pp. 347-380.

Stiny, G., \& Mitchell, W. (1978). The Palladian Grammar. Environment and Planning B, 6, pp. 6-18.

Toledo, L., Natividade, V., \& Vrcibradic, P. (2014). Repensando as Habitações de Interesse Social. Brasília: Letra Capital. 